\title{
Review Article \\ Research Progresses of Flash Evaporation in Aerospace Applications
}

\author{
Wei Ma, ${ }^{1}$ Siping Zhai, ${ }^{2}$ Ping Zhang $\mathbb{D}^{2},{ }^{2}$ Yaoqi Xian, ${ }^{2}$ Lina Zhang, ${ }^{1}$ Rui Shi, ${ }^{1}$ Jiang Sheng, \\ Bo Liu, ${ }^{1}$ and Zonglin $\mathrm{Wu}^{1}$ \\ ${ }^{1}$ Science and Technology on Space Physics Laboratory, Beijing 100076, China \\ ${ }^{2}$ School of Mechanical and Electrical Engineering, Guilin University of Electronic Technology, Guilin 541004, China \\ Correspondence should be addressed to Ping Zhang; zp3631@gmail.com
}

Received 7 June 2018; Accepted 10 October 2018; Published 17 December 2018

Academic Editor: André Cavalieri

Copyright (C) 2018 Wei Ma et al. This is an open access article distributed under the Creative Commons Attribution License, which permits unrestricted use, distribution, and reproduction in any medium, provided the original work is properly cited.

\begin{abstract}
Liquid is overheated and evaporated quickly when it enters into the environment with lower saturation pressure than that corresponding to its initial temperature. This phenomenon is known as the flash evaporation. A natural low-pressure environment and flash evaporation have unique characteristics and superiority in high altitude and outer space. Therefore, flash evaporation is widely used in aerospace. In this paper, spray flash evaporation and jet flash evaporation which are two different forms were introduced. Later, key attentions were paid to applications of flash evaporation in aerospace. For example, the flash evaporation has been used in the thermal control system of an aircraft and the propelling system of a microsatellite and oil supply system of a rocket motor. Finally, the latest progresses in the calculation model and numerical simulation of flash evaporation were elaborated.
\end{abstract}

\section{Introduction}

Liquid will be overheated and thereby evaporated when it enters into the environment with lower saturation pressure than that corresponding to its initial temperature. This phenomenon is called the flash evaporation [1]. Due to strong evaporation behavior, flash evaporation is accompanied with phase changes during absorption of heats. It has been used in more and more fields, including seawater desalination [2], national defense [3], health care $[4,5]$, aerospace [6], and electronic industry [7]. Vacuum and high-altitude environments are a natural low-pressure environment. With this advantage, flash evaporation has been extensively used in the aerospace field.

Recently, aerospace technology develops quickly. Aircrafts and spacecrafts have extensive applications and important significances in civil purpose, military purpose, and scientific exploration. They have become the research hotspot in the world. The former one includes planes, helicopters, and supersonic bomber. The latter one covers space shuttle, man-made earth satellite, manned spacecraft, space probe, and so on. Air vehicles often serve in high altitude or outer space. These spaces are tough environments with low temperature and low pressure. In these environments, air vehicles will experience high temperature and high-speed frictions at running through the atmospheric layers. These hostile environments influence the safe and stable running of air vehicles significantly [8]. This paper mainly addressed the following problems related to the applications of flash evaporation in aerospace:

(1) Air vehicles are equipped with tremendous electronic devices for the accurate control and management. Short-term high-power-consumption running of these electronic devices often will cause sharp temperature rises in local regions $[9,10]$. If heats cannot be eliminated or diffused in time, large-scaled accumulation of heats will exceed the ultimate capacity of electronic devices. This will reduce the reliability of electronic devices and thereby cause failure of devices $[11,12]$. This even will threaten lives of astronauts in a manned spacecraft. Therefore, effective 
heat management has important significance to electronic devices in air vehicles

(2) A microsatellite has characteristics of high functional density, high flexibility, short R\&D period, low R\&D cost, and distributed combination into "virtual macrosatellite." It has become one of three research hotspot and development frontiers in the space technology field at present [13]. With small volume and low mass, a microsatellite can be used for launching of a pencil rocket. Moreover, the propelling system is required to have simple structure, low power consumption, low mass, and large specific impulse. Therefore, a microsatellite and a small satellite are often used in a liquefied gas propulsion program. The liquid propellant was sprayed directly into the outer space, microsatellites, and small satellites to gain thrust.

(3) Large spacecrafts, such as manned spacecrafts and space probes, have to be launched into the outer space at the essential speed by the thrust of the carrier rocket. Later, they make orbital motion based on inertia. The carrier rocket acquires the thrust by the fast full combustion of propellant and the release of high-temperature vapor. However, coking of fuel oil and delayed ignition may occur due to the low spray quality and long evaporation time of fuel oils. These problems restrict the fast high-efficiency combustion of fuel oils. Hence, how to gain high-quality spray and shorten the ignition time becomes key problems that have to be solved urgently in the rocket motor field.

\section{Principle of Flash Evaporation}

The boiling point of liquid working medium is increased with the growth of pressure. On the contrary, the boiling point decreases with the reduction of pressure. For example, the boiling point on the sea level is $100^{\circ} \mathrm{C}$, but it decreases to $90^{\circ} \mathrm{C}$ at high mountains with an altitude of about $3 \mathrm{~km}$. When the ambient pressure of high-temperature and high-pressure liquid drops sharply to lower than the saturated pressure corresponding to its initial temperature, the initial temperature of the liquid is higher than the boiling point under the corresponding pressure. In this case, the liquid is overheated and enters into the thermal imbalance. The liquid is evaporated quickly. This process is called the flash evaporation.

Flash evaporation of single-component liquid is an isenthalpic process. It is generally processed into heat insulation. Therefore, the evaporation capacity in the flash evaporation of the single-component liquid is

$$
X=\frac{H_{u}^{L}-H_{d}^{L}}{H_{d}^{V}-H_{d}^{L}} \times 100,
$$

where $X$ is the mass percentage of evaporated liquid. $H_{u}^{L}$ is the initial enthalpy of liquid under the initial temperature and pressure $(\mathrm{J} / \mathrm{kg}) . H_{d}^{L}$ is the residential enthalpy of liquid under reduced pressure and its corresponding saturation temperature $(\mathrm{J} / \mathrm{kg}) . \quad H_{d}^{V}$ is the vapor enthalpy under reduced pressure and its corresponding saturation temperature $(\mathrm{J} / \mathrm{kg})$.

If the enthalpies of liquid and vapor are unknown, the evaporation capacity can be calculated by the following formula:

$$
X=\frac{C_{p}\left(T_{u}-T_{d}\right)}{H_{v}} \times 100
$$

where $C_{p}$ is the specific heat capacity of the liquid under the initial temperature and pressure $\left(\mathrm{J} /\left(\mathrm{kg} \cdot{ }^{\circ} \mathrm{C}\right)\right) . T_{u}$ is the initial temperature of the liquid $\left({ }^{\circ} \mathrm{C}\right) . T_{d}$ is the saturation temperature of the liquid under the reduced pressure $\left({ }^{\circ} \mathrm{C}\right) . H_{v}$ is the latent heat of evaporation under the reduced pressure and its corresponding saturation temperature $(\mathrm{J} / \mathrm{kg})$.

According to applications of flash evaporation in aerospace, flash evaporation is divided into two forms: spray flash evaporation and jet flash evaporation. The spray flash evaporation has sheltering of the hot surface in the spraying process. The jet flash evaporation has no sheltering of the hot surface. These two forms of flash evaporation are based on the principle of the same pressure drop. The spray flash evaporation is often used in aerospace electron cooling and spacecraft thermal control field. The jet flash evaporation is often used in the propelling system of spacecrafts and the fuel injection system of a rocket motor. Therefore, the spray flash evaporation has one additional process of arriving at the hot surface compared to the jet flash evaporation.

2.1. Spray Flash Evaporation. Spray flash evaporation is mainly used in flash evaporation spray cooling in aerospace. It is the development of spray cooling under the evaporation mode and is used to gain the maximum heat exchange with unit volume of liquid working medium. Under vacuum conditions, flash evaporation spray cooling has unique advantages. The flash evaporation of liquid working medium can remove residual heats of spacecrafts without using other media. Generally, flash evaporation spray cooling is divided into two flash evaporation processes. One is the flash evaporation in the process when liquid drops fly before arriving at the cooled surface. It is called the droplet flash evaporation [6]. Droplets shrink and are cooled during the flash evaporation, thus influencing the temperature and size of the liquid film. The other one is the flash evaporation process when droplets form the liquid film on the cooled surface. It is called the liquid film flash evaporation. This is also the main heat transfer way in flash evaporation spray cooling. The general process of spray flash evaporation is to spray high-pressure liquid onto the low-pressure environment. Droplets are accompanied with flash evaporation impact after being sprayed and hit on the hot surface, forming the liquid film. Subsequently, heats on the hot surface are removed through flash evaporation and boiling of the liquid film. The physical images of flash evaporation spray cooling are shown in Figure 1(a). 


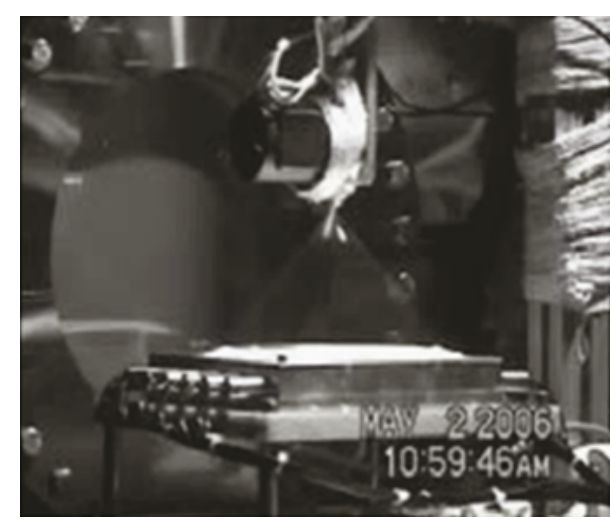

(a)

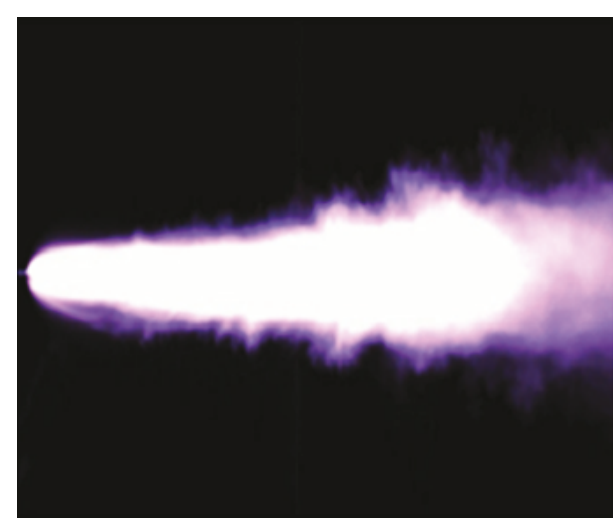

(b)

Figure 1: (a) Physical images of flash evaporation spray cooling [18]. (b) Physical images of jet flash evaporation [19].

2.2. Jet Flash Evaporation. High-pressure liquid is sprayed onto the low-pressure environment, developing flash evaporation in the low-pressure environment after being overheated. This phenomenon is called jet flash evaporation in this paper and is also called the decompression flash evaporation by many scholars [14, 15]. However, it is called jet flash evaporation in order to be distinguished from the spray flash evaporation. The jet flash evaporation images which are recorded by the high-speed camera are shown in Figure 1(b). In aerospace, jet flash evaporation mainly uses the vapor after the jet and acquires the counterforce. This counterforce is used as the propulsion unit of small-sized spacecrafts or is used in the fuel injection system in a rocket motor in order to gain high-quality fuel oil mist. In the internal combustion engine field, the spray flash evaporation of fuel oil is also called the flash boiling $[16,17]$.

\section{Calculation Model and Numerical Simulation}

\subsection{Spray Flash Evaporation}

3.1.1. Droplet Flash Evaporation. Flash evaporation of single droplet in vacuum is a complicated coupling process of heat and material transfer. However, the calculation model and numerical simulation of this process are not perfect yet. Gao et al. [20] established a calculation model of flash evaporation of single lithium chloride droplet in vacuum. In this mode, it was hypothesized that heat transfer only occurs on the droplet surface. Natural convective heat transfer and heat transfer resistance in droplets are overlooked. This will influence the whole flash evaporation to some extent. Gao et al. also studied influences of the radiant heats to correct the calculation model. Isothermal treatment of droplets is performed in the model. However, there are great temperature gradients in droplets in practical conditions. Liu et al. $[21,22]$ proved the great temperature gradients in the droplets throughout the whole flash evaporation in vacuum conditions. Cheng et al. [23] corrected the thermal conductivity of droplets with considerations to influences of temperature gradient and connection on droplets. They also calculated flash evaporation characteristics of submicron droplets in millisecond in the vacuum environment. The energy equation is

$$
\rho_{1} c_{p} \frac{\partial T}{\partial \tau}=\frac{1}{r^{2}} \times \frac{\partial}{\partial r}\left(k_{\mathrm{eff}} r^{2} \frac{\partial T}{\partial r}\right)
$$

where $\rho_{1}$ and $c_{p}$ are the density and specific heat capacity of droplets, respectively. $T$ and $\tau$ are the temperature and time variables, respectively. $k_{\text {eff }}=k \theta$. $k$ and $k_{\text {eff }}$ are the real heat conductivity of droplets and effective heat droplets corrected by convection in droplet, respectively. The mass equation is

$$
\frac{d R}{d \tau}=\frac{\dot{m}}{4 \pi R^{2} \rho_{1}}
$$

where $\dot{m}$ and $R$ are the mass evaporation rate and instantaneous radius of droplets, respectively. The evaporation equation controlled by diffusion is

$$
\dot{m}=-4 \pi R_{g} D_{v}\left(\frac{P_{s}}{T_{s}}-\frac{P_{\infty}}{T_{\infty}}\right)
$$

where $D_{v}$ is the binary diffusion coefficient of droplets. $P_{s}, T_{s}$, $P_{\infty}$, and $T_{\infty}$ are the vapor pressure and temperature on the droplet surface and in the environment. This single-droplet evaporation model is shown in Figure 2. Based on this model, Chen et al. analyzed the influences of ambient pressure, initial diameter, and movement rate of droplets on droplet flash evaporation. They discovered that compared with the isothermal model, the model with effective heat conductivity correction can describe the droplet vacuum flash evaporation more accurately.

Wu et al. [24] established the model to calculate evaporation of droplets in gas space based on the droplet surface diffusion and heat transfer on the droplet external surface under constant temperature boundary conditions. This 


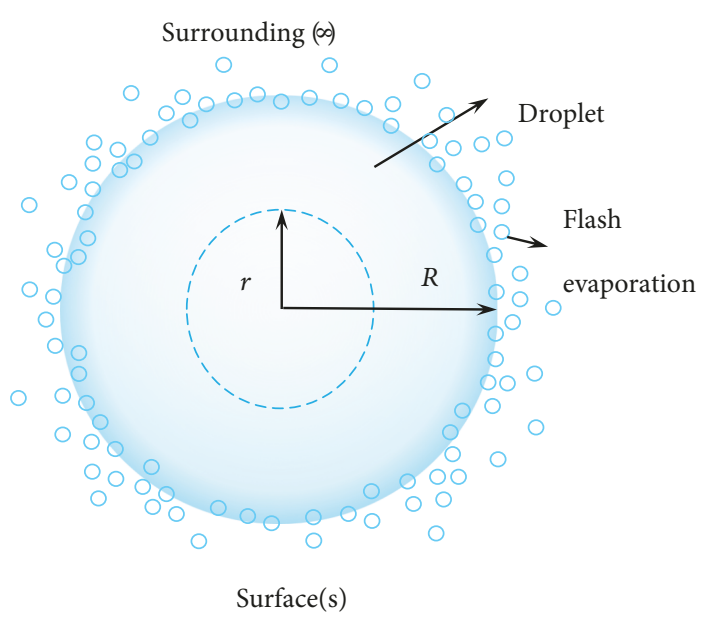

Figure 2: Single-droplet evaporation model.

model calculates the evaporation by combining size changes of single droplets and Fick's first law:

$$
\frac{d D_{d}}{d \tau}=-\frac{8 M r D_{v}}{\rho_{1} D_{d}^{2} R_{g}}\left(\frac{P_{r}}{T_{r}}-\frac{P_{\infty}}{T_{\infty}}\right)
$$

where $D_{d}$ is the droplet diameter. $M$ is the molecular mass of water. $P_{r}$ and $T_{r}$ are the pressure and temperature at the radius $r$. The droplet temperature distribution combines heat transfer between the droplet and environment as well as the evaporation heat transfer of droplets. Temperature changes of droplet are given by the following equation.

$$
\frac{d T}{d t}=-\frac{3}{\rho_{1} c_{d} r^{2}}\left[\frac{\gamma D_{v} M}{R_{g}}\left(\frac{P^{\mathrm{sat}}(T)}{T}-\frac{P_{\infty}}{T_{\infty}}\right)-k\left(T_{\infty}-T\right)\right],
$$

where $c_{d}$ is the droplet concentration. $\gamma$ is the latent heat of evaporation. $P^{\text {sat }}(T)$ is the saturated vapor pressure under the temperature $T$. Changes of the droplet radius meet the following differential equation:

$$
\frac{d r}{d t}=\frac{D_{v} M}{\rho_{1} R_{g} r}\left(\frac{P_{\infty}}{T_{\infty}}-\frac{P^{\mathrm{sat}}(T)}{T}\right) \cdot \frac{2 \lambda+2 r}{2 r+5.35\left(\left(\lambda^{2} / 2 r\right)+3.42 \lambda\right)} .
$$

Wu et al. studied the influences of droplet ambient temperature, humidity, and droplet radius on droplet evaporation according to this model.

Wang et al. [25] reported one vacuum droplet flash evaporation mode different from that of Cheng et al. [23]. In other words, droplets are frozen before arriving at the heating surface. It is believed that droplets have experienced supercooling droplets, mixed droplets, and ice particles before arriving at the heating surface (Figure 3). A complete mathematical model was established to describe this process. They introduced the simple thermal equilibrium

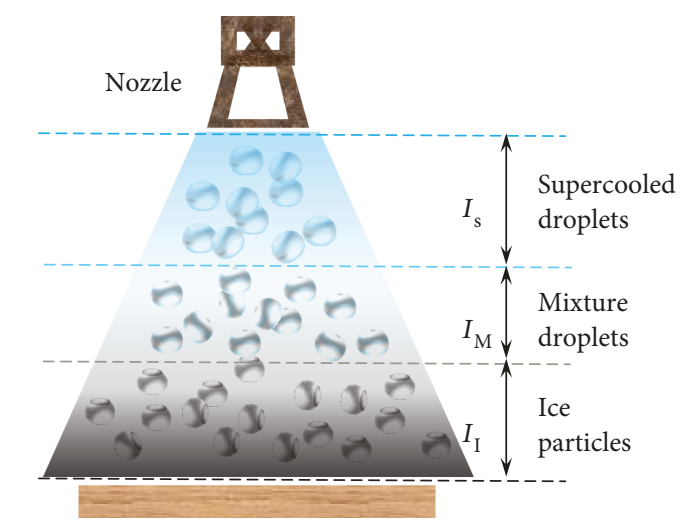

Heating surface

FIGURE 3: Droplet flash evaporation model proposed by Wang et al. [25].

relationship and the phase transition model into Fick's first law to establish a one-dimensional droplet flash evaporation model. Influences of ambient pressure, temperature, droplet size, and droplet concentration on droplet phase transition were studied.

Xi et al. [26] proposed a new flash evaporation model of fuel oil droplets. This model involved the classical uniform nucleon model, Rayleigh bubble growth model, and fresh bubble detonation model. According to calculation results, they divided the flash evaporation into three stages: initial stage, fast growth stage, and final detonation stage. Moreover, the boiling detonation time was related to fuel oil temperature and back pressure.

3.1.2. Film Flash Evaporation. Chen et al. [27] believed that given high flight speed of droplets and small spraying height, droplets could arrive at the cooled surface in a short time. Hence, influences of droplet flash evaporation on spray characteristics could be neglected. The film flash evaporation model established by Cheng et al. is shown in Figure 4 . The film stays in the vacuum environment under the overheating state. It is gasified through flash evaporation and absorbs abundant heats. The heat transfer volume of film flash evaporation can be expressed as

$$
Q_{\text {flash }}=\gamma \frac{d m}{d t}
$$

where $d m / d t$ is the flash evaporation mass flow. It was calculated by the interface mass transfer equation proposed in Reference [28]. This method used the vapor density difference between the two sides of the gas-liquid interface as the power of flash evaporation mass transfer based on the film penetration theory. Below the interface is the saturated vapor density corresponding to the film temperature, and above the interface is the vacuum environment. The mass transfer equation on the gas-liquid interface is

$$
\frac{d m}{d t}=D\left(\rho_{l}-\rho_{s}\right)
$$




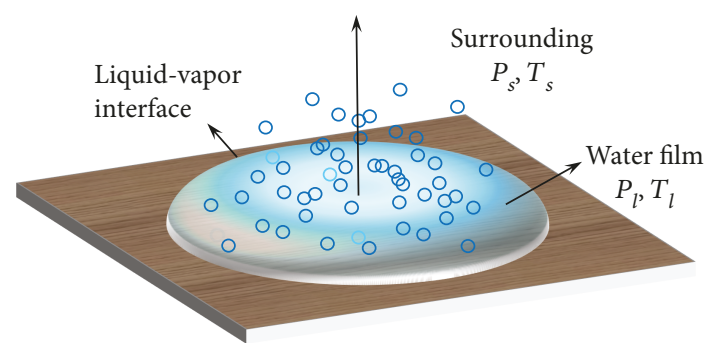

Figure 4: Film flash evaporation model.

where $\rho_{l}$ and $\rho_{s}$ are the saturated vapor densities of the liquid and environment, respectively. $D$ is the mass transfer coefficient. They used water as the working medium and studied the influences of working medium flow on flash evaporation heat transfer according to this model. They also concluded that the higher flow rate of the working medium is accompanied with better performance of vacuum flash evaporation. Accordingly, the heat transfer density is higher and the temperature on the heating surface is lower.

There are few studies on the film flash evaporation model. However, many scholars have carried out numerical simulations on the complete process of spray flash evaporation. Based on a previous study [29], Cheng et al. [23] used pure water as the working medium and established a mathematical model for the extensively complete vacuum flash evaporation spray cooling. The flash evaporation spray cooling system is shown in Figure 5. Cheng et al. [23] pointed out that the flash evaporation spray cooling has five heat transfer processes except for the droplet flash evaporation. These five processes are as follows: (1) heat transfer between droplet and the heating surface (droplet-wall impaction, $Q_{\text {drop }}$ ), (2) flash evaporation heat transfer when droplets arrive at the heating surface and form the liquid film (film flash evaporation, $\left.Q_{\text {flash }}\right)$, (3) convective heat transfer in which the film washes the heating surface (film-surface convective heat transfer, $\left.Q_{\text {film }}\right)$, (4) heat transfer in which the film boils on the heating surface and absorbs heats to generate small bubbles (bubble boiling heat transfer, $Q_{\mathrm{bub}}$ ), and (5) heat emittance of the system to the environment in the spraying process (the system emits heat to the environment, $Q_{\text {envi }}$ ). Therefore, the energy conservation control equation for vacuum flash evaporation spray cooling is

$$
\dot{Q_{\text {in }}}=Q_{\text {drop }}+\dot{Q_{\text {flash }}}+\dot{Q_{\text {film }}}+\dot{Q_{\text {bub }}}+Q_{\text {envi }}^{\dot{*}}
$$

where $Q_{\text {flash }}$ is calculated by the method in Reference [27]. The rest processes can be expressed as follows. $Q_{\text {drop }}$ can be divided into two parts. One is the heat transfer when droplets run through the film:

$$
Q_{\mathrm{drop}, 1}=\frac{\lambda_{\text {film }}}{l_{\text {film }}} \mathrm{Nu}_{\text {film }} \cdot A_{\text {drop }}\left(T_{\text {drop }}-T_{\text {film }}\right),
$$

where $A_{\text {drop }}$ is the surface area of droplets. The other one is the heat transfer when droplets contact the surface. It can be expressed by the ratio between the real heat exchange

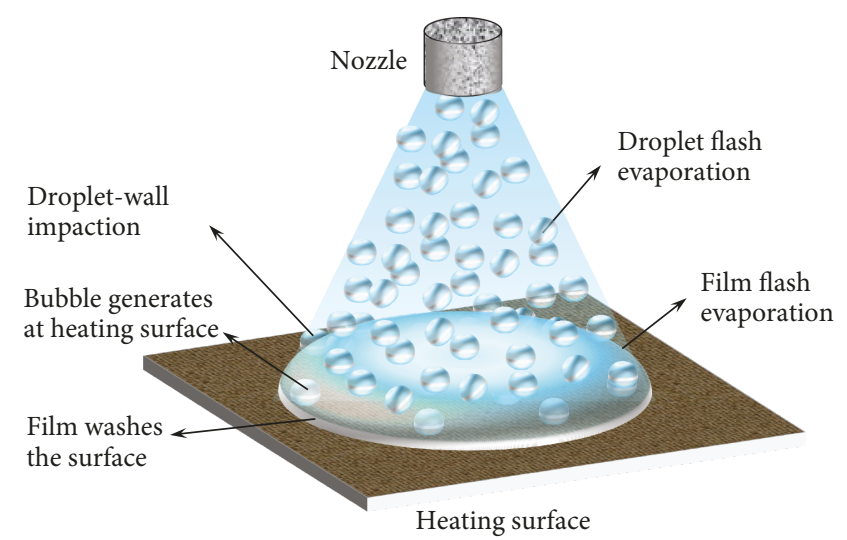

FIgURE 5: The complete vacuum flash evaporation spray cooling model.

and the maximum possible heat transfer. According to the mass conservation equation and momentum conservation law of film movement, the empirical relation equation of $Q_{\text {film }}$ can be gained:

$$
Q_{\text {film }}=\frac{\lambda_{\text {liq }}}{l_{\text {film }}} \mathrm{Nu}_{\text {film }} \cdot A_{\text {film }}\left(T_{w}-T_{\text {film }}\right),
$$

where $\mathrm{Nu}_{\text {film }}$ is the Nusselt number of the film, and the heat transfer of bubbles in the film $\left(Q_{\mathrm{bub}}\right)$ is

$$
Q_{\mathrm{bub}}=\Delta h_{f g} \cdot \frac{d m_{\mathrm{bub}}}{d t}
$$

Since the system can diffuse heat to the vacuum environment through radiation,

$$
Q_{\mathrm{envi}}^{\cdot}=\varepsilon_{w} \sigma A_{w}\left(T_{w}^{4}-T_{\mathrm{envi}}^{4}\right),
$$

where $A_{w}$ is the surface area of the heating surface. Cheng et al. [23] compared the model results and experimental results, achieving good results. Influences of heat transfer characteristics (e.g., surface temperature distribution), spray pressure, spray height, and spray angle on heat transfer were analyzed.

3.2. Jet Flash Evaporation. Jet flash evaporation generally occurs in waste emission of a manned spacecraft, starting blowdown of the rocket engine and fuel injection system of the engine. It influences the safe and effective running of space activities. An experimental study and numerical simulation on characteristics of jet flash evaporation have important significance to prevent its disadvantages and make full use of its advantages.

It is difficult to realize the complicated experimental conditions, such as vacuum environment and flash evaporation of fuel oil. Therefore, many scholars have carried out numerical studies on jet flash evaporation. Fuel oil flash evaporation in the combustor of aeroengine is a complicated nonequilibrium and multicomponent two-phase process. Lee et al. [30] tried to simulate flash evaporation flow of JP-8 fuel oil for the 
first time. They combined the multicomponent surrogate model to predict properties of JP-8 under overheating conditions and flash evaporation under real flight conditions by one multidimensional transient program. Lee et al. discovered that for axisymmetric flow, there is a higher vapor volume in the near-wall region than in the core region. This is caused by the nonuniform mist at the nozzle exit. They also pointed out that the future model must take flash evaporation into account. Li et al. [31] carried out a simulation study on the vacuum jet flow field by using the Fluent software based on the volume of fluid (VOF) method, $\kappa-\varepsilon$ standard turbulence model, and PISO algorithm. They analyzed the vacuum jet flow field under different nozzle diameters and incidence pressures. They discovered that under the same entrance pressure, a larger nozzle diameter brings larger turbulence strength and better atomization effect. Given the fixed nozzle diameter, the jet turbulence strength achieves the best distribution and best jet flow field in the pressure range of 10-15 MPa. Moreover, they discovered that if the solubility of the target polymeric materials is neglected, the acetone solvent has better jet distribution than trichloromethane and carbon tetrachloride. Zhao et al. [32] analyzed three different jet forms which are emitted by vacuum liquid and studied the transfer conditions among different jet forms (continuous liquid jet, partial flash evaporation jet, and complete flash evaporation jet) by a kinetic study. In addition, Zhao et al. also analyzed flow characteristics of liquid flash evaporation jet. The initial supercooling ratio $R_{P, 0}$ was defined to determine the application range of uncompressible jet theory. Avila et al. [33] established a simulation model of jet flash evaporation under the overheating or metastabilization liquid under low pressure. They applied the MacCormack finite difference principle and divided the structural meshing in the simulation region. The conservation equations of mass, momentum, and energy and the real-state equation were constructed and solved. Results conformed well to the experiment. Sim-Ocirc et al. [34] established the one-dimensional numerical model of high-dispersion jet flash evaporation. To solve the saltus equation set, the sudden phase transition on the metastable liquid jet surface was simulated into one evaporation wave. The supersonic speed expansion of the downstream two-phase mixture of the evaporation wave was analyzed from the radial direction. The radial occurrence position of the evaporation wave was predicted. Later, Vieira and Simões-Moreira [35] proved this physical model by the experimental method and observed the blocking behavior as well as the existence of the evaporation wave. Meanwhile, many scholars [35-37] have carried out abundant experiments on jet flash evaporation under low pressure.

\section{Study on Applications of Flash Evaporation in Aerospace}

4.1. Thermal Control System of Air Vehicles. Heat management of electronic elements and heat removal in local hightemperature places in aerospace are important to stable and safe running of air vehicles [38]. However, the hostile environments in outer space, such as thin air and weight loss, have extremely high requirements on cooling technology. The flash evaporation spray cooling is to carry heat on the cooled surface by the liquid film which is formed by the atomized and sprayed droplets through physical phenomena (e.g., flow and flash evaporation boiling). Since the pressure drop of traditional spray cooling $[39,40]$ is not lower than the saturation pressure, no flash evaporation of droplets will occur in the falling process (Figure 6). Many scholars have reviewed the traditional spray cooling [41, 42]. However, the flash evaporation spray cooling accompanied with phase transition has latent heat of vaporization, which can reach the maximum heat dissipating capacity of the working medium. Marcos et al. [43] proved through an experiment that flash evaporation spray cooling has higher coefficient of heat transfer compared with the traditional spray cooling oil. Besides, the flash evaporation spray cooling can lower temperature of the cooled surface effectively. The flash evaporation spray cooling is characteristic of strong heat transfer performance, few working media and no thermal contact resistance on the cooled surface. It possesses a promising application potentials and prospects in heat management of air vehicles. In the outer space, the natural vacuum environment provides a good low-pressure environment for the spray flash evaporation. NASA takes the vacuum flash evaporation cooling as the prior development direction of thermal control in air vehicles [44].

There are few studies on the vacuum-based flash evaporation spray cooling. Aoki [14] carried out a theoretical analysis on the relationship of maximum coefficient of heat transfer and the vapor saturation temperature in flash evaporation under low pressure by using water as the working medium. The analytic expressions of maximum heat flux and maximum coefficient of heat transfer in the small overheating temperature range were deduced. Moreover, Aoki discovered that the maximum heat flux is proportional to the overheating temperature, but it is unrelated to the droplet size. Zhifu et al. [19] studied the spray flash evaporation by using R134a as the working medium and analyzed the characteristics of spray by the high-speed camera, phase Doppler particle analyzer (PDPA), and thermocouple. They give a comprehensive experimental research on the spray and thermal characteristics of the R134a flashing spray. The saturated pressure of R134a freezing medium under $25^{\circ} \mathrm{C}$ was $0.67 \mathrm{MPa}$ [4], which was higher than the ambient pressure. Therefore, it can develop flash evaporation under normal pressure. Zhou et al. [45] also disclosed the coupling influences of low pressure and spray distance on heat transfer characteristics in the spray flash evaporation of R134a. Figure 7(a) shows the droplet diameter $\left(D_{32}\right)$ of spray back pressure at the spray distance of $30 \mathrm{~mm}$. They found that $10 \mathrm{kPa}$ is a transitional pressure, as shown in Figure $7(\mathrm{a})$. When it is below the transitional pressure, the spray becomes more homogenous, and the droplet diameter and velocity decrease much faster. And they present the most suitable spray distance and pressure to achieve higher cooling capacity. Then, they presented a comparative study on spray characteristics of flashing spray with three volatile cryogens (R123a, R407C, and R404A) [4]. The R404A spray has the smallest droplet diameter and the largest droplet velocity, as well as 


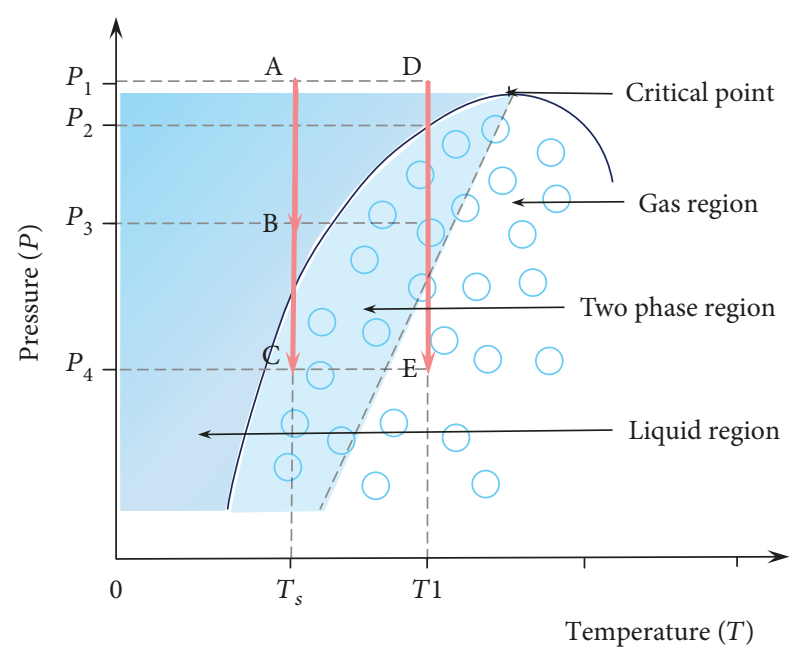

Figure 6: The A-B process is the traditional spray cooling. The A-C process is the flash evaporation spray cooling which is realized by pressure drop. The D-E process is the flash evaporation spray cooling which is realized by temperature rise.

the strongest cooling capacity. Figure 7(b) shows the droplet diameter $\left(D_{32}\right)$ along the spray central line.

In the same time, many scholars have studied by using water as the working medium. Chen et al. [27] studied the vacuum flash evaporation spray cooling by using water as the working medium. They constructed an experimental platform for vacuum flash evaporation spray cooling (Figure $8(\mathrm{a})$ ). In the experiment, the nozzle was a $30^{\circ}$ whirlwind atomized solid nozzle and the experimental room was vacuumized to $3.5 \mathrm{kPa}$ to simulate the vacuum environment. The heating surface in the experimental system was a copper pillar with $12 \mathrm{~mm}$ in diameter and was covered by insulation materials. The lower end was installed with a heater (Figure $8(\mathrm{~b})$ ). The typical working condition of $30^{\circ}$ nozzle angle, $3.3 \mathrm{~mm}$ spray height, and $3.95 \mathrm{~L} \cdot \mathrm{h}^{-1}$ flow rate of working medium was studied in the experiment. Cheng et al. [46] improved the heating system of the heating surface to realize larger heat accumulation (Figure 8(c)). In the experiment, the commercial DANFOSS nozzle which has a pore size of $0.5 \mathrm{~mm}$ and a nozzle angle of $45^{\circ}$ was used. Cheng et al. studied the influences of flow rate and spray height on heat transfer of vacuum flash evaporation cooling. They concluded the optimal flow rate and the optimal spray height. Meanwhile, they also discovered that flash evaporation spray cooling only took $1 / 3$ flow of the traditional spray cooling to eliminate the same heat flux.

4.2. Propelling System of a Microsatellite. A microsatellite attracts wide attentions in the world due to the short R\&D period, low mass, and low cost. It has become an important development direction in the space technology. The propelling system of a microsatellite is mainly restricted by the energy consumption, volume, and weight. A cold air propelling system is used mostly. Although the cold air propelling system has simple structure, the applied gas working medium has low density. Therefore, the gas bottle has large volume and low safety performance. Subsequently, the liquefied propelling system is used more and more in order to increase the storage density. The liquefied propelling system stores gaseous working medium in the liquid state. However, the liquid working medium needs tremendous latent heat of vaporization for revaporization, which has to be supplied by electric energy on the satellite. This restricts the application of the liquefied propelling system significantly.

Wei and Guo [47] designed a flash evaporation jet propulsion program based on the flash evaporation of overheated liquid. In this program, the overheated liquid was sprayed onto the vacuum through the nozzle, developing the flash evaporation. Liquid was vaporized strongly, which generated a counterforce for propulsion. Such propelling mode was called the "flash evaporation jet propulsion program based on liquefied gas." Heat in the flash evaporation of the liquid working medium comes from sensible heat of residual liquid, which reduces demands for external energy sources. Wei and Li [48] compares the cold gas propulsion with the flash evaporation jet propulsion using the same thruster, as shown in Table 1. Compared with the conventional cold gas propulsion program, the flash evaporation jet propulsion program has higher storage density, higher density special impulse, and lower storage pressure. They used liquid ammonia as the working medium in the ground test and flight test. They have achieved satisfying results. The test error of the thrust between the ground test and the flight test is $5 \%$ to $15.5 \%$. The accompanied microsatellite (BX-1) of Shenzhou No.7 applied the flash evaporation jet propulsion program by using liquid ammonia for the first time [48]. The principle is shown in Figure 9. It was tested superior for high-density-specific impulse, low system energy consumption, and simple structure. It is a propelling system suitable to a microsatellite. Table 2 shows the flight verification data for the flash evaporation jet propulsion system.

A hot-water rocket engine uses the liquid water as the propellant. The working process is mainly divided into two stages: heating and release. Water in the pressure vessel is heated firstly until reaching the preset pressure and temperature. The nozzle jet is blocked against release, and the propellant is sprayed to produce the thrust. Flow in the nozzle jet can be viewed as the process that high-temperature and high-pressure water forms the gaseous flow and liquid flow through decompression flash evaporation [49]. The basic working principle of a hot-water rocket engine is shown in Figure 10. Since the hot-water rocket engine has high reutilization and high running safety and is environmental friendly, it can be used as the microsatellite thruster [50]. Adirim et al. [51] reviewed the development process of hot-water propelling technology and its applications on earth and space science. Sun et al. [50] designed the experimental system for the hot-water rocket engine. They obtained the influencing laws of initial pressure, nozzle diameter, and water addition on ballistics attributes in the engine. They found that the specific impulse of the engine is highly sensitive to initial pressure, but it is unrelated to the nozzle diameter or water addition. The conventional calculation formula of rocket thrust is inapplicable to a hot-water rocket engine. Sun et al. [50] also compared the thrust of the hot-water rocket engine, superheated steam rocket engine, and conventional 


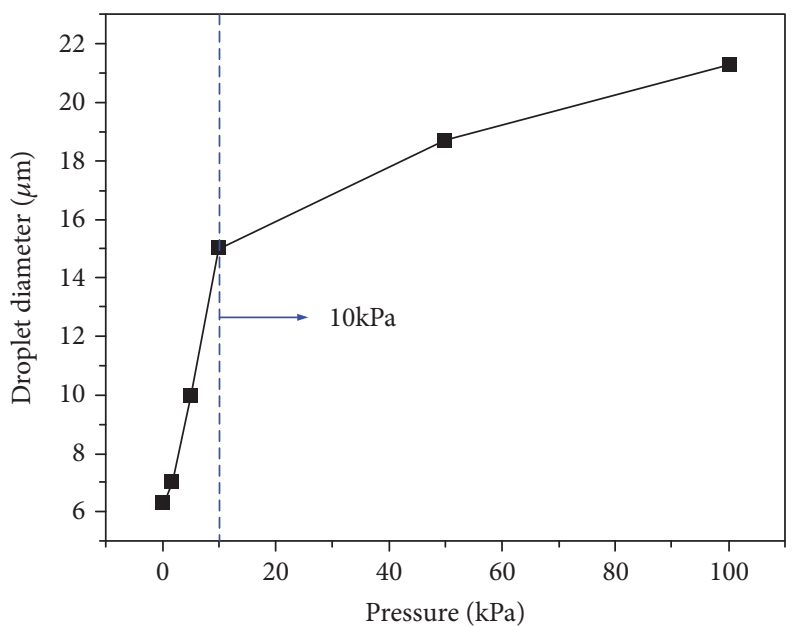

- R134a

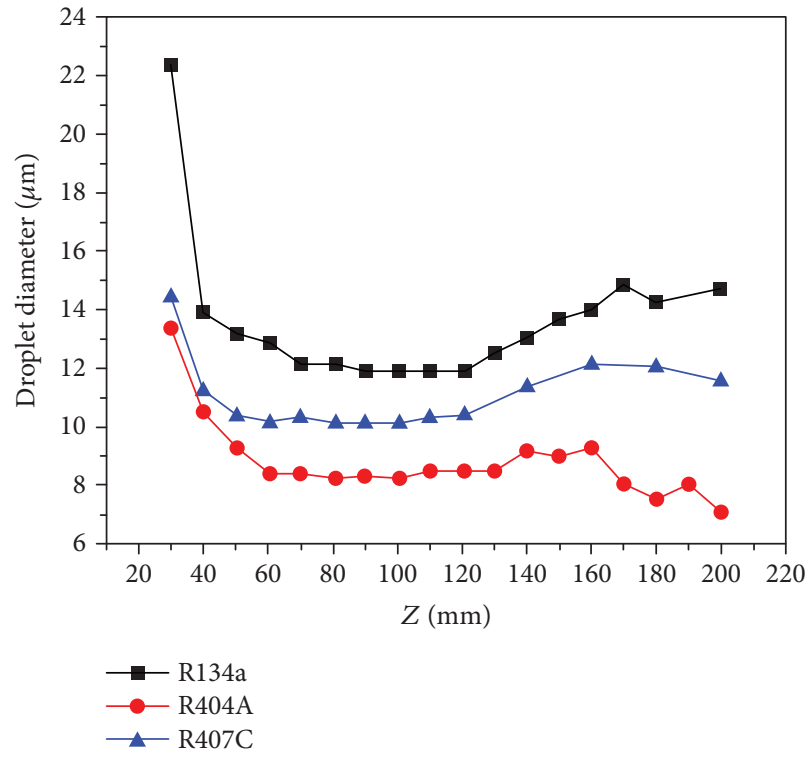

(b)

(a)

Figure 7: (a) Droplet diameter $\left(D_{32}\right)$ of spray back pressure at the spray distance of $30 \mathrm{~mm}$ [45]. (b) Droplet diameter $\left(D_{32}\right)$ along the spray central line [4].

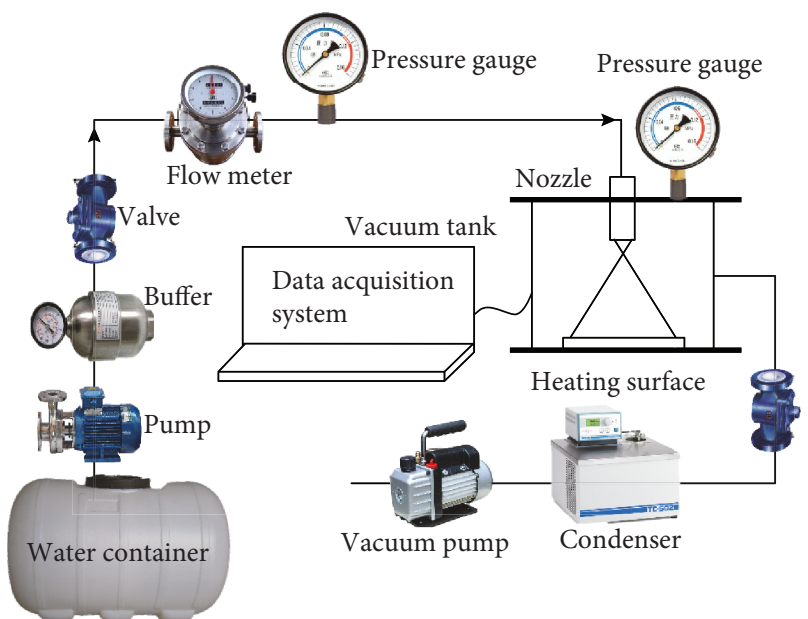

(a)

Heating surface

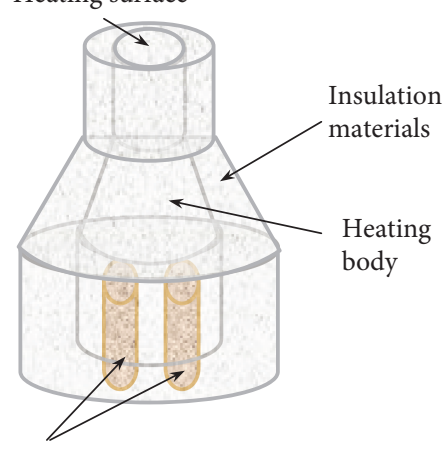

Electrical heating rod

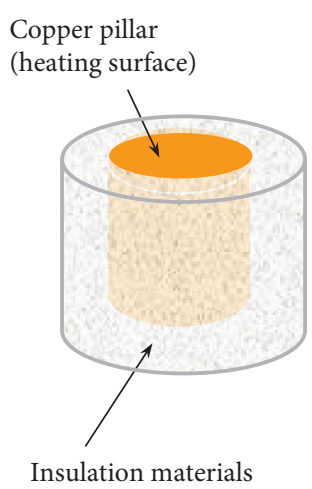

(b)

(c)

FIGURE 8: (a) Experimental system of the vacuum flash evaporation spray cooling [27]. (b) Heating system on the heating surface. (c) The improved heating system on the heating surface. 
TABLe 1: Propulsive performances of cold gas propulsion and flash evaporation jet propulsion [48].

\begin{tabular}{|c|c|c|c|}
\hline & Cold gas propulsion & Flash evaporation jet propulsion & Remarks \\
\hline Pattern & Phase change occurs in the tank & Phase change occurs in the nozzle throat & \\
\hline Thrust & $585 \mathrm{mN}$ & $860 \mathrm{mN}$ & $0.86 \mathrm{MPa}$ \\
\hline Special impulse & $1108 \mathrm{Ns} / \mathrm{kg}$ & $343 \mathrm{Ns} / \mathrm{kg}$ & $0.86 \mathrm{MPa}$ \\
\hline Density special impulse & $7501 \mathrm{Ns} / \mathrm{m}^{3}$ & $209271 \mathrm{Ns} / \mathrm{m}^{3}$ & $0.86 \mathrm{MPa}$ \\
\hline Characteristic & $\begin{array}{l}\text { The liquid-gas conversion is sufficient, } \\
\text { the pressure in the tank drops rapidly, } \\
\text { and the thrust is unstable }\end{array}$ & $\begin{array}{l}\text { The liquid-gas conversion is incomplete, } \\
\text { the pressure in the tank is basically stable, } \\
\text { and the thrust is constant }\end{array}$ & \\
\hline Heat control demand & Larger power thermal control is required & Larger power thermal control is not required & \\
\hline
\end{tabular}

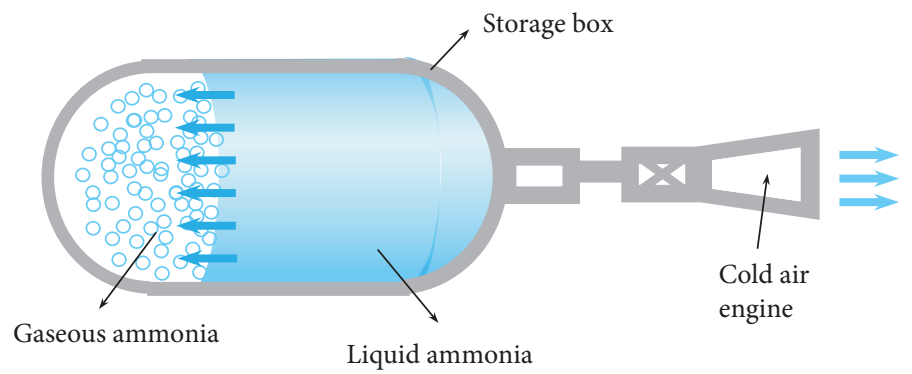

FIGURE 9: Working principle of the flash evaporation jet propulsion program.

TABLE 2: Flight verification data for the propulsion system [48].

\begin{tabular}{|c|c|c|c|c|c|c|}
\hline $\begin{array}{l}\text { Order } \\
\text { number }\end{array}$ & $\begin{array}{l}\text { Velocity increment } \\
(\mathrm{m} / \mathrm{s})\end{array}$ & $\begin{array}{l}\text { Operation time } \\
(\mathrm{s})\end{array}$ & $\begin{array}{l}\text { Initial tank pressure } \\
(\mathrm{MPa})\end{array}$ & $\begin{array}{l}\text { Propellant remainder } \\
(\mathrm{g})\end{array}$ & $\begin{array}{c}\text { Propulsion } \\
\text { efficiency }\end{array}$ & Remarks \\
\hline 1 & - & 15.36 & 0.657 & 977.44 & - & $\begin{array}{l}\text { Test } \\
\text { spray }\end{array}$ \\
\hline 2 & 0.4624 & 28.67 & 0.707 & 917.74 & 0.9467 & \\
\hline 3 & 0.5092 & 32.77 & 0.667 & 852.00 & 0.9664 & \\
\hline 4 & 0.1001 & 7.17 & 0.685 & 839.08 & 0.8494 & \\
\hline 5 & 0.1281 & 9.22 & 0.682 & 822.54 & 0.8497 & \\
\hline 6 & 0.3169 & 20.48 & 0.675 & 781.63 & 0.9554 & \\
\hline 7 & 0.1898 & 13.31 & 0.669 & 757.13 & 0.8500 & \\
\hline 8 & 0.0949 & 7.17 & 0.653 & 744.88 & 0.8451 & \\
\hline 9 & 0.5217 & 34.82 & 0.656 & 681.00 & 0.9534 & \\
\hline 10 & 0.5115 & 33.79 & 0.645 & 618.37 & 0.9796 & \\
\hline 11 & 0.5131 & 33.79 & 0.638 & 555.74 & 0.9935 & \\
\hline 12 & 0.5170 & 33.79 & 0.648 & 492.43 & 0.9856 & \\
\hline 13 & 0.5077 & 33.77 & 0.648 & 430.38 & 0.9684 & \\
\hline 14 & 0.4941 & 32.77 & 0.647 & 369.88 & 0.9728 & \\
\hline 15 & 0.5002 & 32.77 & 0.657 & 308.63 & 0.9698 & \\
\hline 16 & 0.4978 & 31.74 & 0.673 & 247.67 & 0.9728 & \\
\hline 17 & 0.4092 & 29.70 & 0.722 & 203.17 & 0.7965 & \\
\hline 18 & 0.4187 & 29.70 & 0.727 & 156.42 & 0.8094 & \\
\hline 19 & 0.4060 & 29.70 & 0.717 & 111.92 & 0.7958 & \\
\hline 20 & 0.4187 & 29.70 & 0.727 & 65.17 & 0.8094 & \\
\hline
\end{tabular}

rocket engine, as shown in Table 3. It can be seen that the thrust of the hot-water rocket engine is the highest in a certain time. Next, Sun and Wei [52] simulated the flow field in hot-water rocket nozzle by numerical simulation. They divided the flow in nozzle into the single-phase flow process, flash evaporation process, and expand-accelerating process. The hot-water rocket engine is also used for rocketassisted takeoff for plane, glide in the high-speed maglev 

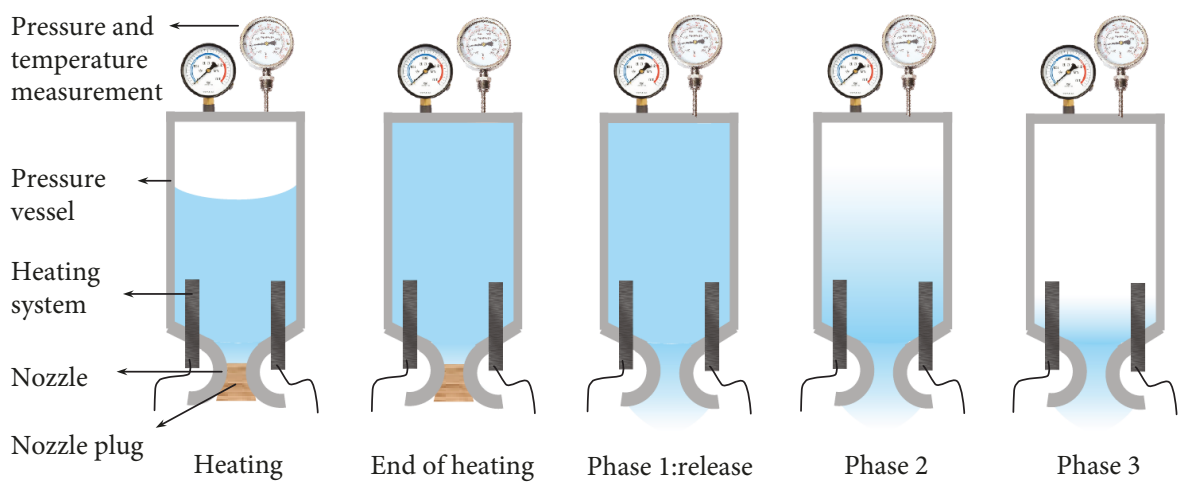

Figure 10: Basic working principle of the hot-water rocket.

TABle 3: The thrust of the hot-water rocket engine, superheated steam rocket engine, and conventional rocket engine [50].

\begin{tabular}{lccc}
\hline $\begin{array}{l}\text { Initial } \\
\text { pressure } \\
(\mathrm{MPa})\end{array}$ & $\begin{array}{c}\text { Hot-water } \\
\text { rocket engine } \\
(\mathrm{N})\end{array}$ & $\begin{array}{c}\text { Superheated steam } \\
\text { rocket engine }(\mathrm{N})\end{array}$ & $\begin{array}{c}\text { Conventional } \\
\text { rocket engine } \\
(\mathrm{N})\end{array}$ \\
\hline 13.6 & 1616.2 & 957.9 & 1120.8 \\
7.15 & 670.3 & 484.4 & 548.2 \\
\hline
\end{tabular}

vehicle track, impetus in the field of supersonic wind tunnel, vehicle sliding and booster in the collision experiments for the start and acceleration, and so on. And a two-stage hotwater rocket (AQUARIUS X-PRO) had been successfully launched [53]. It is noteworthy that due to the complexity of the hot-rocket engine working process, its working performance requires further theoretical research.

4.3. Oil Supply System of the Rocket Engine. Different from the propelling system of the microsatellite, the rocket engine provides power to large spacecrafts or spaceships. It requires large thrust and has more complicated structure and heavier weight compared with a microsatellite. The basic principle of a liquid rocket engine is introduced as follows. The propellant is injected by the injector into the combustor. Next, it is atomized, evaporated, mixed, and burned to generate combustion products. The combustion products are ejected at a high speed, which gives a thrust to the rocket engine. Atomization and mixing of liquid fuels are vital to the successful ignition and complete combustion of the rocket engine. Many scholars and universities have carried out many studies according to the fast evaporation in liquid flash evaporation.

Flash phenomenon may be developed at the spraying of fuel oil from the high-pressure environment to the lowpressure environment or at the heating of fuel oil in the rocket engine. Lecourt et al. [54] discovered that flash evaporation spraying increases the droplet speed and decreases the droplet size. Thompson and Heister [55] made a series of visible experimental studies on flash evaporation in the injector with a large aspect ratio. They found that flash evaporation can improve the atomization characteristics and fuel oil mixing performances and increase the combustion efficiency. In the doctoral dissertation, Thompson [56] studied the flash evaporation in many injectors with large aspect ratios through visible experiments and recorded details.

Pulsed detonation engine (PDE) is a new conceptual engine that generates thrust by intermittent or pulsed detonation waves. Pulse detonation engines are generally available in two forms. One form of PDE is the airbreathing PDE. It absorbs oxygen from the air as the oxidizing agent. Another form is the pulsed detonation rock engine (PDRE) with an oxidant. The air-breathing PDE has same basic working principle with PDE. Compared with traditional engine, PDE has simpler structure, lower cost, smaller weight and higher flight Mach number [57]. However, spraying and mixing of the liquid fuel are a key technological challenge. The existence of fuel oil droplets after the atomization hinders the detonation process. The high-performance atomizing nozzle can split fuel oil into $25 \mu \sim 70 \mu$. Subsequently, the split fuel oil is mixed with hot air. Fuel oil has to be evaporated before combustion. If fuel oil droplets exist, they will absorb the ignition energy and relieve the ignition restricted combustion temperature [58]. Therefore, increasing the evaporation speed of fuel oil is the key to increase the PDE performance.

The United States Air Force (USAF) Laboratory designed a flash evaporation system of fuel oil and carried out abundant studies to address this problem. Tucker et al. [59] designed and constructed a high-pressure fuel oil flash evaporation system. They heated the fuel oil to high-temperature and high-pressure by electric heating method, and then sprayed to the low-pressure environment. Fuel oil will develop flash evaporation immediately after overheated. The flash evaporation of fuel oil makes the fuel oil fully evaporated and mixed with air completely before the ignition. It eliminates the evaporation time of fuel oil droplets, shortens the ignition time and increases the combustion efficiency. In the same time, influences of octane number on ignition time and deflagration to detonation transition (DDT) time were discussed. It concluded that the ignition time was unrelated to the octane number. Both trend and magnitude of DDT are related to the octane number. Figure 11 shows the DDT time of the heptane and isooctane. Isooctane is difficult to be detonated and is lower than the stable CJ (Chapman-Jouget) wave velocity. The n-heptane is easy to be detonated and can reach or exceed the CJ wave speed. Subsequently, Tucker et al. [58] tested four different volatilities. 


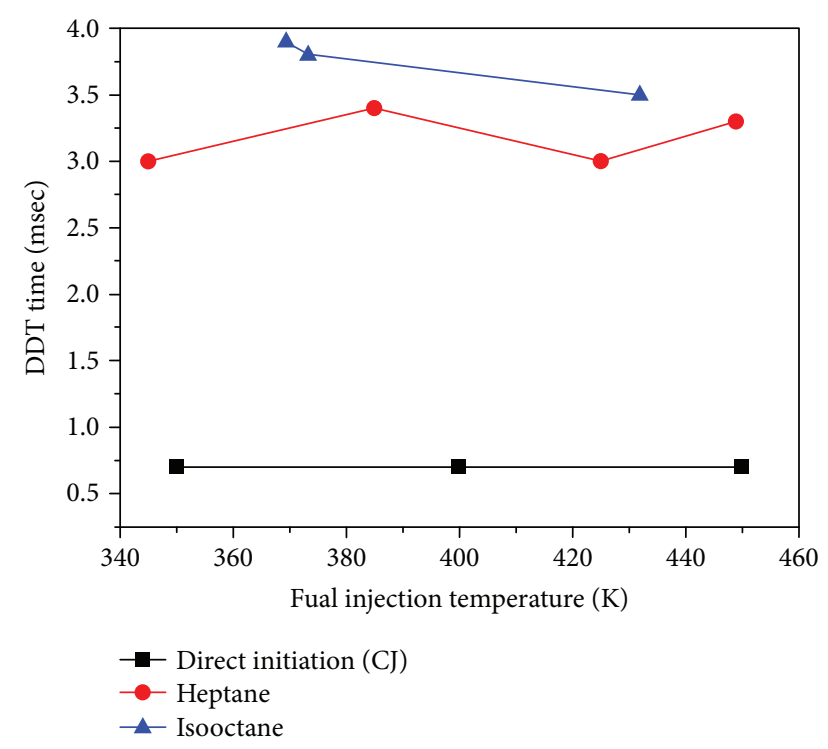

Figure 11: The DDT time of the heptane and isooctane [59].

Fuel oils with different octane numbers included the n-heptane, isooctane, aircraft fuel and JP-8. Results demonstrated that flash evaporation system of fuel oil can provide the flammable mixture of these fuel materials quickly, without coking blockage of the pipelines. The first success in flash evaporation in the working PDE was achieved and JP-8 with low vapor pressure is denoted. On this basis, working conditions needed for complete flash evaporation of JP-8/ air mixture were concluded. In the doctoral dissertation, Tucker [60] introduced the experimental process and detailed characterizations. Miser et al. [61] heated the fuel oil by the waste heats in the thrust tube of PDE in the flash evaporation system of fuel oil. They make JP-8 reached the stable flash evaporation successfully.

The Northwestern Polytechnical University also made associated studies. The research team of Fanwei constructed the testbed for the flash evaporation system of fuel oil to address the influences of fuel oil droplets against the PDE performance. They made a series of preliminary experiments by using water as the working medium. Li et al. [62] carried out a series of experimental studies on the indirect detonation starting of PDRE. Experimental results demonstrated that ignition delay and DDT starting time are not main factors that influence the improvement frequency of fuel oil and oxygen PDRE. According to experimental results, the flame jet ignition can make detonation starting quickly in the shorter distance. Fan et al. [63] studied influences of fuel oil preprocessing on PDRE performance. Preprocessing includes fuel oil waste heat and adding additives. They chose three fuel additives including triethylamine (TEA, $\mathrm{C}_{6} \mathrm{H}_{5} \mathrm{~N}$ ), butylated hydroxytoluene (BHT) and MPG-GAPS (product of FFI Company). The residual working heats of PDRE were collected by the coaxial reverse heat exchanger to heat the fuel oil. Figure 12(a) shows the average maximum operation time of PDRE in various conditions. Figure 12(b) shows the variation detonation initiation time with operation time.
Results showed that studying preheating of fuel oil can shorten the detonation time and prolong the PDRE operation time significantly. Adding additives in the liquid kerosene also can shorten the detonation time and increase the explosibility of fuel materials. Recently, Wang et al. [64] studied the temperature distribution and thermal load in two-phase PDRE through a series of experiments. The thermal load in the propagation stage distributes evenly, but it distributes unevenly in the DDT stage.

Although there are many studies on PDRE and PDE, they are just in the laboratory test and there are still many key problems that have to be studied.

Ionic liquid propellant has high stability, environmentalfriendly and equivalent energy with hydrazine propellant. As an alternative to the hydrazine propellant in the orbital thrusters, it has attracted the attention of many researchers [65]. However, there are rare studies on the multicomponent mixed jetting process of ionic liquid propellants. Especially the spray behavior under vacuum conditions is unknown. Hendrich and Schlechtriem [66] from the Germany Astronavigation Center made a visual experimental study on flash evaporation behavior of Ammonium Dinitramide (ADN)based ionic liquid propellants under vacuum condition. For the convenience of processing, urine was used in the experiment instead of ADN. Besides, influences of nozzle configurations were analyzed. The experiments demonstrated that the geometry parameters of the injectors have the biggest effect on the spray process. The salt concentration had lesser influence on the flashing behavior. Later, Hendrich et al. [67] also predicted the flash evaporation behavior of ADN-based ionic liquid propellant through numerical simulation. Results conformed well to experimental results.

Besides, spacecrafts and air vehicles will discharge waste liquid and blowdown of propellants to vacuum during the flight or mission execution. In this process, liquid materials develop flash evaporation upon the sharp pressure drop. This will cause large-scaled freezing of liquid, blockage of the discharge channels, and freezing of the air vehicle surface. These will influence the safe running of air vehicles significantly. The liquid flash evaporation has been used in the AmericaRussian space station. Hence, many scholars have carried out abundant studies in order to protect the safe stable running of air vehicles $[37,68]$. In this paper, key attentions were paid to applications of flash evaporation, which was not introduced in detail here.

\section{Conclusions and Prospects}

This paper focuses on the application of flash evaporation technology in aerospace. Although there are many studies concerning the application of flash evaporation in aerospace, it is still in the development stage. Some conclusions and prospects are proposed.

\subsection{For the Theoretical Studies}

(1) Flash evaporation spray cooling is a complicated coupling of heat transfer process and mass transfer process. The existing mathematical model is not 


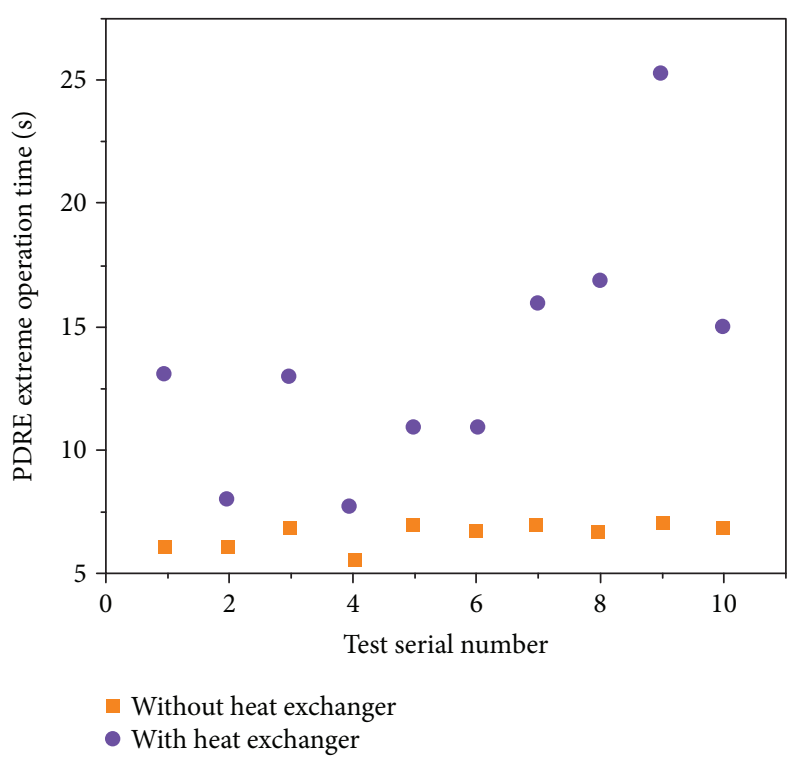

(a)

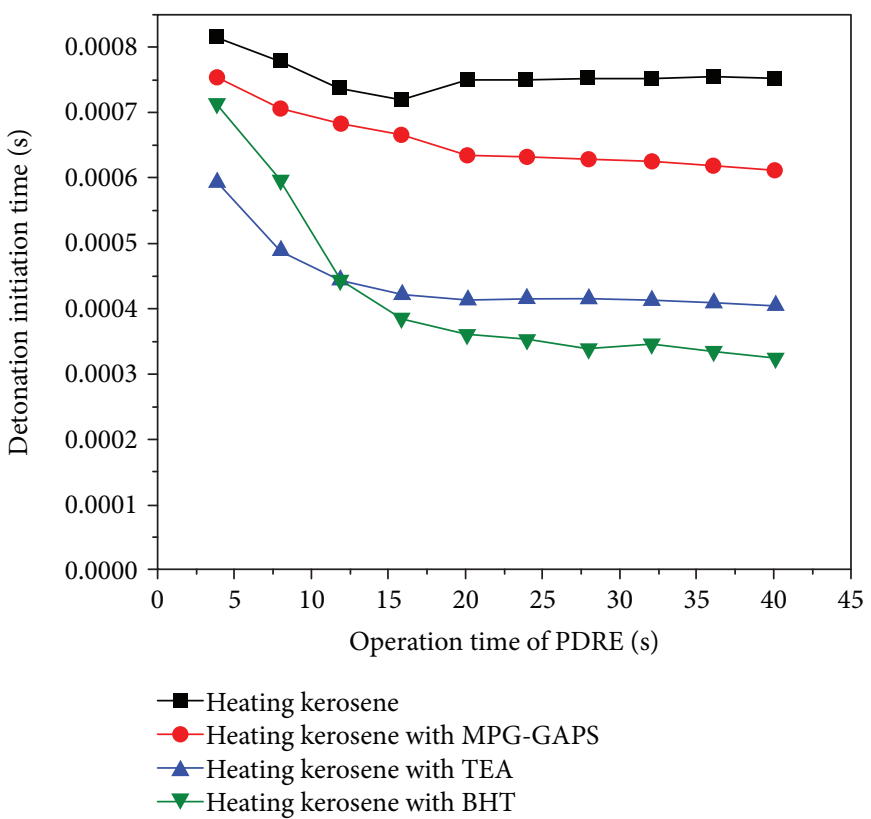

(b)

FIgURE 12: (a) The DDT time of the heptane and isooctane. (b) The variation detonation initiation time with operation time [63].

mature to describe the flash evaporation spray cooling. Many scholars studied the droplet flash evaporation and film flash evaporation independently. These two processes influence mutually. Droplet size and speed influence the film thickness significantly. Therefore, establishing a complete and simple mathematical model of flash evaporation spray cooling has important guidance to future studies

(2) Due to the complexity of droplet flash evaporation, scholars prefer to make many hypotheses to droplet flash evaporation. Everyone hypothesized that droplets keep unchanged spherical shape in the flash evaporation. However, flash evaporation is a strong process during which maintaining the spherical shape of droplets is difficult. Scholars can make further studies on this problem

(3) Nowadays, the vacuum jet flash evaporation has different classifications. There is no public accepted and universal model to describe the complete process of vacuum jet flash evaporation. In future, scholars can attempt to make uniform complete description of the vacuum jet flash evaporation

\subsection{For the Experimental Studies}

(1) The flash evaporation spray cooling has high coefficient of heat transfer and good environmental adaptability. It is applicable to heat management of spacecrafts. However, the studies of flash evaporation spray cooling are not comprehensive compared with the conventional spray cooling. Many researchers proposed the theoretical models to study the process of the flash evaporation spray cooling. At the meantime, the flash evaporation spray cooling with water and volatile cryogens as working medium has been studied. Due to the complexity of flash evaporation spray cooling, it still stays in the experimental stage. Studies on flash evaporation spray cooling only focus on droplet size, impact speed, nozzle type, and spray angle. In future, scholars should study the flash evaporation spray cooling with reference to conventional spray cooing. Influences of roughness of heating surface, different scales and geometric structure of the heating surface, multiscale geometric structure of the heating surface, multinozzle array form, cooling medium, and mixed cooling media on heat transfer in flash evaporation spray cooling are discussed

(2) The propelling systems of a microsatellite, including flash evaporation jet propulsion program and hotwater rocket engine, have been studied for a long time. They have been successfully applied to practical engineering. But the working medium is single. In the future, mixed working medium can be considered to adapt to complex situations.

(3) Adding the flash evaporation system of fuel oil to the PDRE can improve combustion efficiency. Domestic and foreign scholars have conducted a large number of experimental studies on different fuels. And some researchers used the residual working heats of PDRE to improve the flash evaporation system of fuel oil. They all achieved good results. But the flash evaporation system of fuel oil in the PDRE is only in the experimental stage, and there are still many key problems that have to be studied 


\section{Conflicts of Interest}

The authors declare that they have no conflicts of interest.

\section{Authors' Contributions}

Wei Ma and Siping Zhai contributed equally to this work.

\section{Acknowledgments}

This work was supported by the Guangxi Colleges and Universities Program of Innovative Research Team and Outstanding Talent, the National Natural Science Foundation of China (Project no. 51506033), the Innovation Project of GUET Graduate Education (Project no. 2016YJCX18), and the Guangxi Natural Science Foundation (Grant no. 2017JJA160108).

\section{References}

[1] H. T. Shin, Y. P. Lee, and J. Jurng, "Spherical-shaped ice particle production by spraying water in a vacuum chamber," Applied Thermal Engineering, vol. 20, no. 5, pp. 439-454, 2000.

[2] S. Goto, Y. Yamamoto, T. Sugi, T. Yasunaga, Y. Ikegami, and M. Nakamura, "Construction of simulation model for spray flash desalination system," Electrical Engineering in Japan, vol. 170, no. 4, pp. 9-17, 2010.

[3] J.-X. Wang, Y.-Z. Li, H.-S. Zhang et al., "Investigation of a spray cooling system with two nozzles for space application," Applied Thermal Engineering, vol. 89, pp. 115-124, 2015.

[4] Z.-F. Zhou, B. Chen, R. Wang, and G.-X. Wang, "Comparative investigation on the spray characteristics and heat transfer dynamics of pulsed spray cooling with volatile cryogens," Experimental Thermal and Fluid Science, vol. 82, pp. 189197, 2017.

[5] J.-M. Tian, B. Chen, D. Li, and Z.-F. Zhou, "Transient spray cooling: similarity of dynamic heat flux for different cryogens, nozzles and substrates," International Journal of Heat and Mass Transfer, vol. 108, Part A, pp. 561-571, 2017.

[6] W.-L. Cheng, W.-W. Zhang, H. Chen, and L. Hu, "Spray cooling and flash evaporation cooling: the current development and application," Renewable and Sustainable Energy Reviews, vol. 55, pp. 614-628, 2016.

[7] W.-L. Cheng, W.-W. Zhang, S.-D. Shao, L.-J. Jiang, and D.-L. Hong, "Effects of inclination angle on plug-chip spray cooling in integrated enclosure," Applied Thermal Engineering, vol. 91, pp. 202-209, 2015.

[8] P. L. Moses, V. L. Rausch, L. T. Nguyen, and J. R. Hill, "NASA hypersonic flight demonstrators-overview, status, and future plans," Acta Astronautica, vol. 55, no. 3-9, pp. 619-630, 2004.

[9] S. Zhai, P. Zhang, Y. Xian, J. Zeng, and B. Shi, "Effective thermal conductivity of polymer composites: theoretical models and simulation models," International Journal of Heat and Mass Transfer, vol. 117, pp. 358-374, 2018.

[10] P. Zhang, J. Zeng, S. Zhai, Y. Xian, D. Yang, and Q. Li, “Thermal properties of graphene filled polymer composite thermal interface materials," Macromolecular Materials and Engineering, vol. 302, no. 9, article 1700068, 2017.

[11] P. Zhang, P. Yuan, X. Jiang et al., "A theoretical review on interfacial thermal transport at the nanoscale," Small, vol. 14, no. 2, article 1702769, 2018.
[12] Y. Xian, P. Zhang, S. Zhai, P. Yuan, and D. Yang, "Experimental characterization methods for thermal contact resistance: a review," Applied Thermal Engineering, vol. 130, pp. 15301548, 2018.

[13] V. Baturkin, "Micro-satellites thermal control-concepts and components," Acta Astronautica, vol. 56, no. 1-2, pp. 161170, 2005.

[14] I. Aoki, "Analysis of characteristics of water flash evaporation under low-pressure conditions," Heat Transfer-Asian Research, vol. 29, no. 1, pp. 22-33, 2000.

[15] I. Aoki, "Analysis on characteristics of water flash evaporation under low pressure circumstances," Transactions of the Japan Society of Mechanical Engineers Series B, vol. 64, no. 620, pp. 1167-1172, 1998.

[16] Z. Wang, C. Jiang, H. Xu, T. Badawy, B. Wang, and Y. Jiang, "The influence of flash boiling conditions on spray characteristics with closely coupled split injection strategy," Applied Energy, vol. 187, pp. 523-533, 2017.

[17] Y. Huang, S. Huang, R. Huang, and G. Hong, "Spray and evaporation characteristics of ethanol and gasoline direct injection in non-evaporating, transition and flash-boiling conditions," Energy Conversion and Management, vol. 108, pp. 68-77, 2016.

[18] D. M. Althausen and E. L. Golliher, Testing of An r134a Spray Evaporative Heat Sink, SAE Technical Papers 2008-01-2165, 2008.

[19] Z. Zhifu, W. Weitao, C. Bin, W. Guoxiang, and G. Liejin, "An experimental study on the spray and thermal characteristics of R134a two-phase flashing spray," International Journal of Heat and Mass Transfer, vol. 55, no. 15-16, pp. 4460-4468, 2012.

[20] W. Z. Gao, W. Z. Sun, K. Anderson, Y. P. Cheng, and A. Li, "Investigation on temperature distribution of flash evaporation of $\mathrm{LiCl}$ droplets released into vacuum," International Journal of Heat and Mass Transfer, vol. 74, pp. 414-420, 2014.

[21] L. Liu, Q. Bi, and H. Li, "Experimental investigation on flash evaporation of saltwater droplets released into vacuum," Microgravity Science and Technology, vol. 21, no. S1, pp. 255-260, 2009.

[22] L. Liu, Q. C. Bi, and G. X. Wang, "Dynamics of evaporation and cooling of a water droplet during the early stage of depressurization," in Volume 9: Heat Transfer, Fluid Flows, and Thermal Systems, Parts A, B and C, pp. 1777-1785, Lake Buena Vista, FL, USA, 2009.

[23] W. Cheng, H. Chen, L. Hu, and W. W. Zhang, "Effect of droplet flash evaporation on vacuum flash evaporation cooling: modeling," International Journal of Heat and Mass Transfer, vol. 84, pp. 149-157, 2015.

[24] Y. Wu, X. Zhang, and X. Zhang, "Simplified analysis of heat and mass transfer model in droplet evaporation process," Applied Thermal Engineering, vol. 99, pp. 938-943, 2016.

[25] C. Wang, R. Xu, Y. Song, and P. Jiang, "Study on water droplet flash evaporation in vacuum spray cooling," International Journal of Heat and Mass Transfer, vol. 112, pp. 279-288, 2017.

[26] X. Xi, H. Liu, M. Jia, M. Xie, and H. Yin, "A new flash boiling model for single droplet," International Journal of Heat and Mass Transfer, vol. 107, pp. 1129-1137, 2017.

[27] C. Hua, C. Wen-Long, and Z. Wei-Wei, "Numerical study on the effect of spray parameters on heat transfer performance of vacuum flash evaporation cooling," Journal of Engineering Thermophysics, vol. 10, pp. 3783-3788, 2014. 
[28] Y. Junjie, Z. Dan, D. Wei, and G. Yingli, "Experimental investigation of the instantaneous mass transfer coefficient at steam-liquid interface during water film flash evaporation in closed chamber," Journal of Xi'an Jiaotong University, vol. 42, no. 5, pp. 515-518, 2008.

[29] R. Zhao, W. Cheng, Q. Liu, and H. L. Fan, "Study on heat transfer performance of spray cooling: model and analysis," Heat and Mass Transfer, vol. 46, no. 8-9, pp. 821-829, 2010.

[30] J. Lee, R. Madabhushi, C. Fotache, S. Gopalakrishnan, and D. Schmidt, "Flashing flow of superheated jet fuel," Proceedings of the Combustion Institute, vol. 32, no. 2, pp. 32153222, 2009.

[31] J. C. Li, Y. Han, Y. Sun, X. H. Jian, and D. C. Ba, "Study of the jet flow field of vacuum spray process," Thin Solid Films, vol. 520, no. 2, pp. 891-895, 2011.

[32] J. F. Zhao, D. W. Fang, and K. Li, "Thermal dynamics (Pembroke, Ont.) on liquid discharge into vacuum environment," Journal of Engineering Thermophysics, vol. 3, pp. 564567, 2015.

[33] J. Avila, M. Vieira, M. Pimenta, and J. Simões-Moreira, "Liquid jet flashing into a low pressure environment: a numerical solution," in 39th AIAA Thermophysics Conference, Miami, FL, USA, 2007.

[34] J. R. Sim-Ocirc, Es-Moreira, M. M. Vieira, and E. Angelo, "Highly expanded flashing liquid jets," Journal of Thermophysics and Heat Transfer, vol. 16, no. 3, pp. 415-424, 2002.

[35] M. M. Vieira and J. R. Simões-Moreira, "Low-pressure flashing mechanisms in iso-octane liquid jets," Journal of Fluid Mechanics, vol. 572, pp. 121-144, 2007.

[36] W.-F. du, K. Li, S. Wang, and J.-F. Zhao, "Flashing liquid jets in low-pressure environment," Interfacial Phenomena and Heat Transfer, vol. 1, no. 2, pp. 173-180, 2013.

[37] X. X. Lu, L. Li, K. H. Luo, X. B. Ren, Y. Liu, and X. F. Yan, "Investigation on the dispersal characteristics of liquid breakup in vacuum," Journal of Thermophysics and Heat Transfer, vol. 30, no. 2, pp. 410-417, 2016.

[38] J. Doty, K. Yerkes, L. Byrd et al., "Dynamic thermal management for aerospace technology: review and outlook," Journal of Thermophysics and Heat Transfer, vol. 31, no. 1, pp. 8698, 2017.

[39] J.-X. Wang, Y.-Z. Li, G.-C. Li, K. Xiong, and X. Ning, "Investigation of a gravity-immune chip-level spray cooling for thermal protection of laser-based wireless power transmission system," International Journal of Heat and Mass Transfer, vol. 114, pp. 715-726, 2017.

[40] Y. Wang, Y. Jiang, W. Chen, and B. Zhou, "Heat transfer characteristics of spray cooling beyond critical heat flux under severe heat dissipation condition," Applied Thermal Engineering, vol. 123, pp. 1356-1364, 2017.

[41] G. Liang and I. Mudawar, "Review of spray cooling-part 1: single-phase and nucleate boiling regimes, and critical heat flux," International Journal of Heat and Mass Transfer, vol. 115, Part A, pp. 1174-1205, 2017.

[42] G. Liang and I. Mudawar, "Review of spray cooling-part 2: high temperature boiling regimes and quenching applications," International Journal of Heat and Mass Transfer, vol. 115, Part A, pp. 1206-1222, 2017.

[43] A. Marcos, L. C. Chow, J.-H. Du, S. Lei, D. P. Rini, and J. J. Lindauer, "Spray cooling at low system pressure," in Proceedings 2002 (Cat.No.02CH37311) Eighteenth Annual IEEE
Semiconductor Thermal Measurement and Management Symposium, pp. 169-175, San Jose, CA, USA, March 2002.

[44] E. Golliher, J. Romanin, H. Kacher et al., Development of the Compact Flash Evaporator System for Exploration, SAE Technical Paper Series 2007-01-3204, 2007.

[45] Z. Zhou, B. Chen, R. Wang, F. L. Bai, and G. X. Wang, "Coupling effect of hypobaric pressure and spray distance on heat transfer dynamics of R134a pulsed flashing spray cooling," Experimental Thermal and Fluid Science, vol. 70, pp. 96-104, 2016.

[46] W.-L. Cheng, Y.-H. Peng, H. Chen, L. Hu, and H.-P. Hu, "Experimental investigation on the heat transfer characteristics of vacuum spray flash evaporation cooling," International Journal of Heat and Mass Transfer, vol. 102, pp. 233-240, 2016.

[47] W. Qing and G. Shangqun, "Application of the flashing jet propulsion," Journal of Rocket Propulsion, vol. 3, pp. 19-23, 2010.

[48] W. Qing and L. Yongce, “Technology of ammonia flashing jet propulsion in BX-1 satellite," Manned Spaceflight, vol. 18, no. 1, pp. 86-91, 2012.

[49] S. Wei-Wei, W. Zhi-Jun, T. Huan, and W. Ning-Fei, "Numerical simulation of flow field in nozzle of hot water rocket motor," Journal of Propulsion Technology, vol. 35, no. 10, pp. 1426-1433, 2014.

[50] S. Wei-Wei, L. Shi-Peng, W. Zhi-Jun, T. Huan, and W. NingFei, "Experimental investigation on hot water rocket engine," Journal of Propulsion Technology, vol. 34, no. 6, pp. 854-859, 2013.

[51] H. Adirim, R. Lo, N. Pilz, and M. Kreil, "Hot water propulsion development status for earth and space applications," in 42nd AIAA/ASME/SAE/ASEE Joint Propulsion Conference \& Exhibit, Sacramento, CA, USA, 2006.

[52] W. W. Sun and Z. J. Wei, "Numerical analysis of the flow field in the nozzle of hot water rocket motor," Advanced Materials Research, vol. 1016, pp. 635-639, 2014.

[53] M. Kolditz, N. Pilz, H. Adirim, P. Rudloff, M. Gorsch, and M. Kron, "Overview of current hot water propulsion activities at Berlin University of Technology," in Proceedings of the 2nd International Conference on Green Propellants for Space Propulsion, pp. 35-47, Chia Laguna (Cagliari), Sardinia, Italy, 2004.

[54] R. Lecourt, P. Barricau, and J. Steelant, "Spray velocity and drop size measurements in flashing conditions," Atomization and Sprays, vol. 19, no. 2, pp. 103-133, 2009.

[55] A. S. Thompson and S. D. Heister, "Characteristics of flashing flows within a high aspect ratio injector," Atomization and Sprays, vol. 26, no. 7, pp. 633-658, 2016.

[56] A. S. Thompson, Visualization of Cavitating and Flashing Flows within a High Aspect Ratio Injector. Doctor Dissertation, Purdue University, West Lafayette, 2014.

[57] K. M. Pandey and P. Debnath, "Review on recent advances in pulse detonation engines," Journal of Combustion, vol. 2016, Article ID 4193034, 16 pages, 2016.

[58] K. C. Tucker, P. I. King, and F. R. Schauer, "Hydrocarbon fuel flash vaporization for pulsed detonation combustion," Journal of Propulsion and Power, vol. 24, no. 4, pp. 788-796, 2008.

[59] C. Tucker, P. King, R. Bradley, and F. Schauer, "The use of a flash vaporization system with liquid hydrocarbon fuels in a pulse detonation engine," in 42nd AIAA Aerospace Sciences Meeting and Exhibit, Reno, Nevada, 2004. 
[60] K. C. Tucker, A Flash Vaporization System for Detonation of Hydrocarbon Fuels in a Pulse Detonation Engine. Doctor Dissertation, Air University, Ohio, 2005.

[61] C. Miser, P. King, and F. Schauer, "PDE flash vaporization system for hydrocarbon fuel using thrust tube waste heat," in 41st AIAA/ASME/SAE/ASEE Joint Propulsion Conference \& Exhibit, Tucson, Arizona, 2005.

[62] J. Li, W. Fan, C. Yan, and Q. Li, "Experimental investigations on detonation initiation in a kerosene-oxygen pulse detonation rocket engine," Combustion Science and Technology, vol. 181, no. 3, pp. 417-432, 2009.

[63] Z.-C. Fan, W. Fan, H.-y. Tu, J.-L. Li, and C.-j. Yan, “The effect of fuel pretreatment on performance of pulse detonation rocket engines," Experimental Thermal and Fluid Science, vol. 41, pp. 130-142, 2012.

[64] Y. Wang, K. Wang, W. Fan et al., "Experimental study on the wall temperature and heat transfer of a two-phase pulse detonation rocket engine," Applied Thermal Engineering, vol. 114, pp. 387-393, 2017.

[65] Q. Zhang and J.'n. M. Shreeve, "Ionic liquid propellants: future fuels for space propulsion," Chemistry - A European Journal, vol. 19, no. 46, pp. 15446-15451, 2013.

[66] C. Hendrich and S. Schlechtriem, "Flashing behavior of ionic liquid propellants under vacuum conditions," in 51st AIAA/ SAE/ASEE Joint Propulsion Conference, Orlando, FL, USA, 2015.

[67] C. Hendrich, L. Gury, and S. Schlechtriem, "Predicting flashing phenomena: a combined approach of numerical simulation and experiments," in 52nd AIAA/SAE/ASEE Joint Propulsion Conference, Salt Lake City, UT, USA, 2016.

[68] M. Birouk and N. Lekic, "Liquid jet breakup in quiescent atmosphere: a review," Atomization and Sprays, vol. 19, no. 6, pp. 501-528, 2009. 


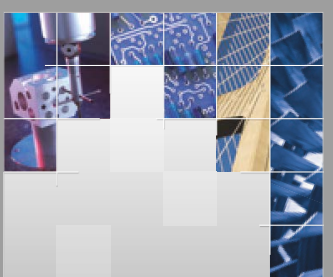

\section{Enfincering}
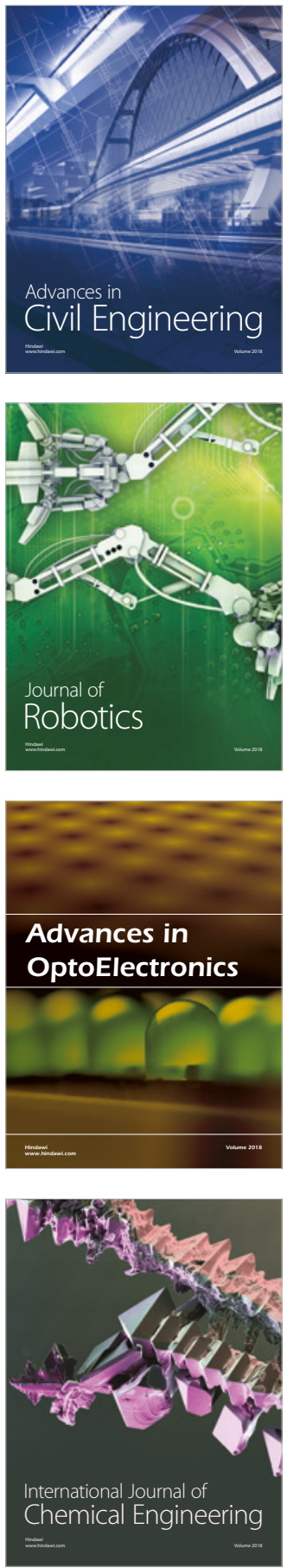

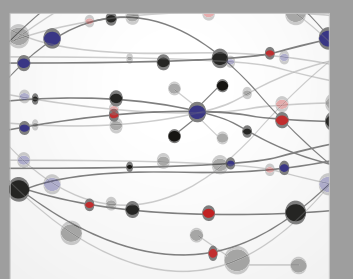

\section{Rotating \\ Machinery}

The Scientific World Journal

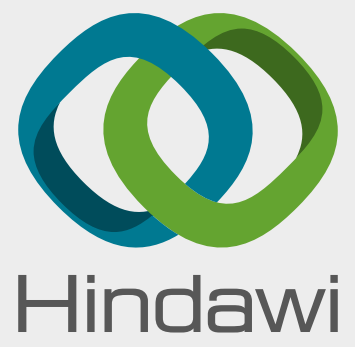

Submit your manuscripts at

www.hindawi.com
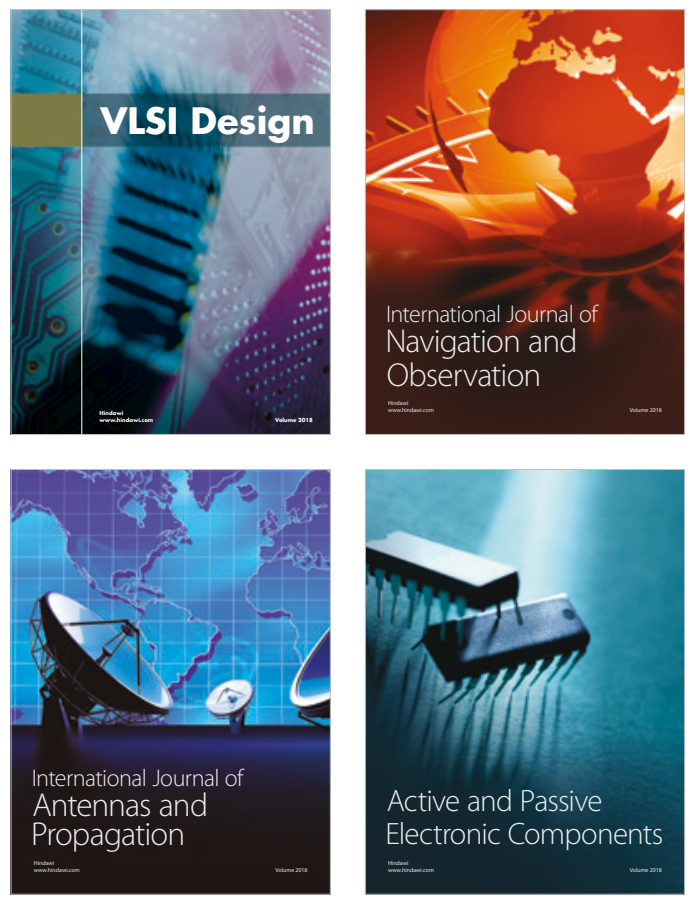
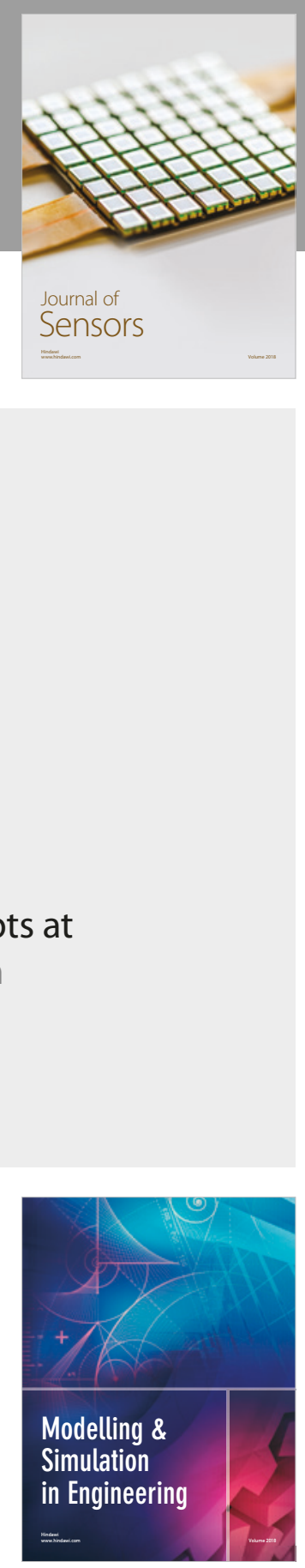

\section{Advances \\ Multimedia}
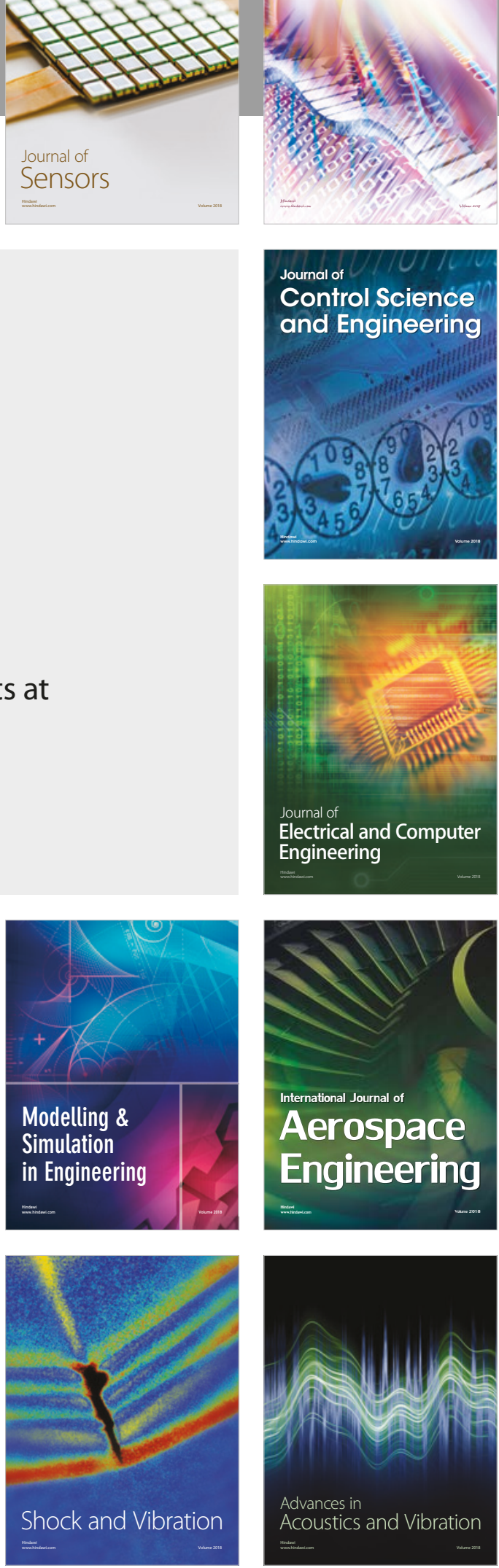